\title{
Development of a Coil-Shape Photocatalysis-Plasma Synergistic Reactor for a Practical and Long-Term Usable Air-Cleaner
}

\author{
Tsuyoshi Ochiai1,2*, Yuji Hayashi ${ }^{3}$, Erina Ichihashi ${ }^{3}$, Tadashi Machida ${ }^{4}$, Yoshitsugu Uchida ${ }^{4}$, \\ Shoko Tago', Yuko Morito' ${ }^{2,5}$, Akira Fujishima1,2 \\ ${ }^{1}$ Kanagawa Academy of Science and Technology, Kawasaki, Japan \\ ${ }^{2}$ Photocatalysis International Research Center, Tokyo University of Science, \\ Chiba, Japan \\ ${ }^{3}$ I'm PACT World Co. Ltd., Tokyo, Japan \\ ${ }^{4}$ TANASHIN DENKI Co. Ltd., Tokyo, Japan \\ ${ }^{5} \mathrm{U}$-VIX Corporation, Tokyo, Japan \\ Email: ${ }^{*}$ pg-ochiai@newkast.or.jp
}

Received 7 April 2014; revised 13 May 2014; accepted 20 May 2014

Copyright (C) 2014 by authors and Scientific Research Publishing Inc.

This work is licensed under the Creative Commons Attribution International License (CC BY).

http://creativecommons.org/licenses/by/4.0/

(c) (i) Open Access

\section{Abstract}

A novel air-cleaner with a coil-shape photocatalysis-plasma synergistic reactor was developed. The air-cleaner showed $95 \% \pm 1 \%$ reduction of a TVOCs concentration in tobacco smoke at "single-pass" condition. Air-purification activity of the air-cleaner was stably-maintained after the treatment of 12,000 cigarettes of tobacco smoke.

\section{Keywords}

Photocatalysis, Plasma Treatment, Synergy, Volatile Organic Compounds, Air-Cleaner

\section{Introduction}

Recently, we have proposed an effective method for the separation of smoking area by using "sandwich-shape" photocatalysis-plasma synergistic reactors [1]. The reactor consists of two essential technologies: plasma as-

${ }^{*}$ Corresponding author.

How to cite this paper: Ochiai, T., et al. (2014) Development of a Coil-Shape Photocatalysis-Plasma Synergistic Reactor for a Practical and Long-Term Usable Air-Cleaner. American Journal of Analytical Chemistry, 5, 467-472.

http://dx.doi.org/10.4236/ajac.2014.58055 
sisted catalytic technology (PACT) reactor [2] and a $\mathrm{TiO}_{2}$ impregnated Ti-mesh filter $\left(\mathrm{TMiP}^{\mathrm{TM}}\right)$ [3]. Synergistic effects of photocatalysis and plasma excitation achieve the significant oxidative decomposition of gaseous compounds in tobacco smoke. Based on this result, we have fabricated the "coil-shape" PACT-TMiP reactor to reduce electrostatic capacity, pressure drop, and noise level for a long-term usability. A practical air-cleaner using the reactor was fabricated and installed in a real-scale smoking room. The air-purification ability and the long-term usability of the air-cleaner in the smoking room were confirmed.

\section{Materials and Methods}

Figure 1(a) and Figure 1(b) show a photograph and a schematic illustration of a coil-shape PACT-TMiP synergistic reactor. Basic designs and fabrication methods of PACT reactor and TMiP were described previously [2] [3]. Two pieces of TMiP sheets were introduced in the inside of a Ni-plated coil. The atmospheric dielectric barrier discharge between the outer electrode and the coil produces air plasma around the TMiP sheets when AC voltages applied. In the present study, we used a voltage of $10 \mathrm{kV}$ (peak-to-peak), a frequency of $25 \mathrm{kHz}$, and a power of $45 \mathrm{~W}$. Air can be blown through the gaps of coil-shape reactor while maintaining high level of surface contact with TMiP and air-plasma. Figure 1(c) shows schematic illustrations of both outside and inside of the practical air-cleaner using the coil-shape reactor. A high efficiency particulate air (HEPA) filter, ten coil-shape reactors, two ozone-cut filters, an activated carbon filter, and a fan were arranged inside the casing. When the fan is turned on, air flow is generated inside the casing from the air inlet toward the air outlet, passed through the filters and the PACT-TMiP reactor. Electrostatic capacity of the reactor was measured between the inner electrode with TMiP and outer-electrode shown in Figure 1(b) by a LCR700 LCR meter (Sanwa Electric Instrument Co., Ltd., Tokyo) at $10 \mathrm{kHz}$. Pressure drop was measured between before and after of the reactor array simultaneously at the central position of the air-cleaner shown in Figure 1(c) by a DG70 differential pressure gauge (NAGANO KEIKI Co., Ltd., Tokyo).

A schematic illustration of the test method for evaluation of air-purification activity of the air-cleaner is shown in Figure 2. The real-scale smoking room with the air-cleaner was fabricated as a test room. Air flow is generated inside the smoking room from the air inlet toward the air outlet, passed through the air-cleaner. In this condition, the smoking room was always filled with tobacco smoke from the sequential simultaneous burning of eight cigarettes. By-products were deposited on the surface of electrodes according to increasing the amounts of burning cigarettes, which may affect both the stability and reliability of PACT-TMiP reactor. In order to remove the by-products on the electrodes, air-cleaner operates for 15 min without burning cigarettes after every 200 cigarettes of tobacco smoke treatment. Odor concentrations, total suspended particulates (TSPs), and total volatile organic compounds (TVOCs) concentrations were calculated after the treatments of 8, 6000 and 12,000 cigarettes of tobacco smoke at the sampling points 1 and 2 in Figure 2 as follows. Odor concentrations were calculated by three point comparison type smell bag method [4]. TSPs were monitored by using a digital real-time LD-3K2 dust monitor (Sibata Scientific Technology Ltd., Tokyo). TVOCs concentrations were calculated by the qualitative and quantitative analyses using gas chromatography with a flame ionization detector (GC-FID) as described elsewhere [5]. Samples were collected by drawing $60 \mathrm{~L}(0.6 \mathrm{~L} / \mathrm{min})$ of air through a charcoal tube, desorbed with carbon disulfide, and analyzed by GC-FID. TVOCs concentrations were calculated for all compounds eluted between n-hexane and n-hexadecane, calibrated and converted to toluene equivalents. Similar details about removal ratios of the three amounts were calculated from the formula $\left(A_{1}-A_{2}\right) / A_{1}$, where $A_{1}$ and $\mathrm{A}_{2}$ are the amounts at the sampling point 1 and 2, respectively. An important point is that tobacco smoke was treated by the air-cleaner just once, i.e. this is a "single-pass" system. Noise level was also measured at the air outlet of the air-cleaner ( $1 \mathrm{~m}$ height and $1 \mathrm{~m}$ length from the air-cleaner) shown in Figure 2 by a NL-31 sound level meter (RION Co., Ltd., Tokyo).

\section{Results and Discussion}

\subsection{Comparison of Reactor Properties of the Air-Cleaners}

Table 1 summarized electrostatic capacity, pressure drop, and noise level of the air-cleaners. The values in Table 1 show the total amount of installed reactors on the air-cleaners (12 reactors for previous type, 10 reactors for present type). The present air-cleaner using "coil-shape" reactor shows smaller values than the previous aircleaner using "sandwich-shape" reactor in all parameters. Especially reducing of the electrostatic capacity is 


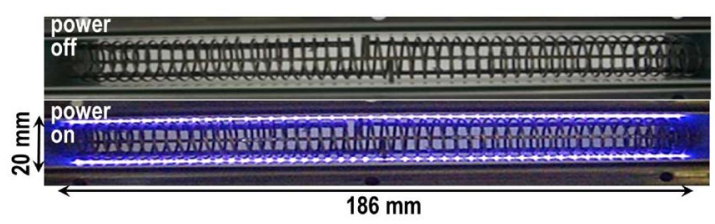

(a)

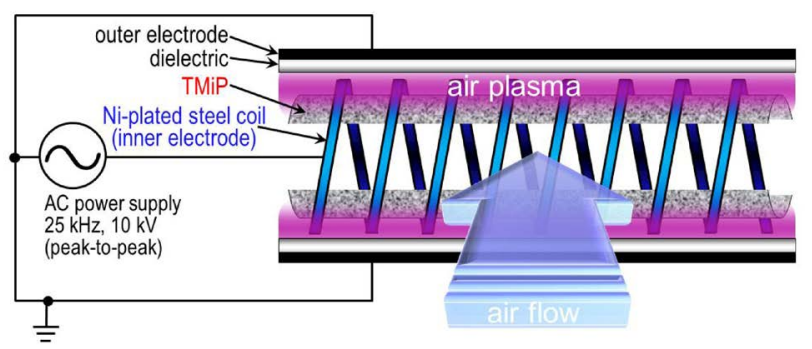

(b)
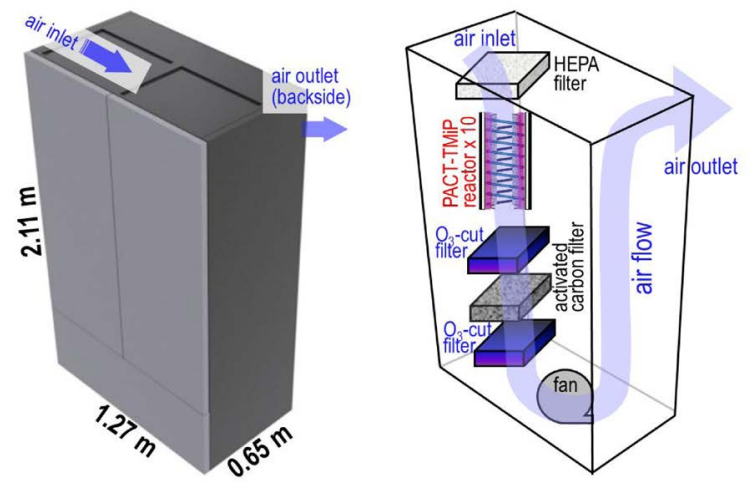

(c)

Figure 1. (a) A photograph of the coil-shape PACT-TMiP synergistic reactor; (b) A schematic illustration of the reactor; (c) A schematic illustration of the practical air-cleaner.

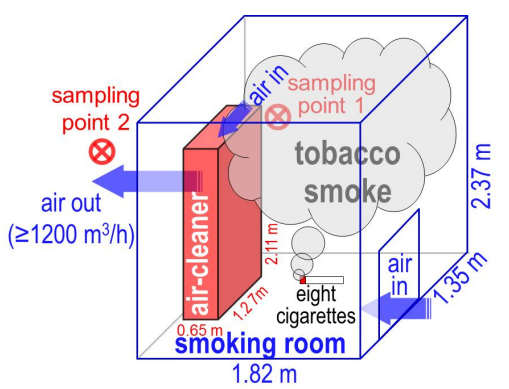

Figure 2. A schematic illustration of the proposed test method in the real-scale smoking room for evaluation of air-purification ability of the air-cleaner. Sampling points 1: air inlet of the air-cleaner; 2 : air outlet of the air-cleaner.

important for energy saving and long-time usage. It is thought that the performance of air flow is improved by the change of reactor shape from "sandwich" to "coil".

\subsection{Removal Ratios of Compounds by the Air-Cleaner}

Figure 3 shows removal ratios of the three amounts in tobacco smoke by the air-cleaner. After the treatment of 8 
Table 1. Comparison of electrostatic capacity, pressure drop, and noise level of the air-cleaners.

\begin{tabular}{cccc}
\hline Reactor type & Electrostatic capacity (pF) & Pressure drop (Pa) & Noise level (dB) \\
\hline Previous type ("sandwich”) [1] & 2050 & 370 & 80 \\
Present type (“coil”) & 374 & 70 & 60 \\
\hline
\end{tabular}

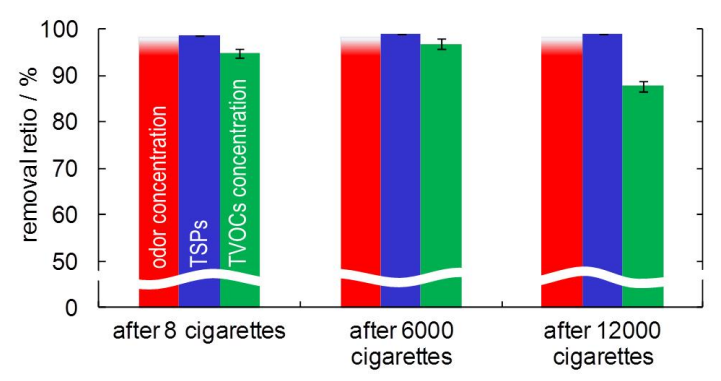

Figure 3. The removal ratios of the three amounts in tobacco smoke by the air-cleaner (after 8, 6000 and 12,000 cigarettes). Red: odor concentration; blue: TSPs; green: TVOCs concentration.

cigarettes of tobacco smoke, $A_{1}$ of the odor concentration, TSPs, and TVOCs concentration were 550, $296.6 \pm$ $17.5 \mu \mathrm{g} / \mathrm{m}^{3}$, and $433 \pm 93 \mu \mathrm{g} / \mathrm{m}^{3}$, respectively. On the other hand, $A_{2}$ of the amounts were $\leq 10$ (under the detection limit), $4.4 \pm 0.2 \mu \mathrm{g} / \mathrm{m}^{3}$, and $23 \pm 5 \mu \mathrm{g} / \mathrm{m}^{3}$. Thus, removal ratios of the amounts were $\geq 98,98.5 \pm 0.1$, and $95 \%$ $\pm 1 \%$. These values indicate that the air-cleaner is able to decompose and/or remove the compounds efficiently similar to the tendency previously reported by using the air-cleaner with "sandwich-shape" reactor [1]. Therefore, a low-cost and energy-saving operation was achieved by reducing the electrostatic capacity and pressure drop while maintaining the high air-purification ability of the synergistic effect. Moreover, the removal ratios of the amounts were kept at high-level ( $\geq 98,98.9 \pm 0.1$, and $88 \% \pm 1 \%$ ) after the treatment of 12,000 cigarettes of tobacco smoke, which is equivalent to using the air-cleaner in the smoking room for a half year.

The photocatalysis-plasma synergistic reactor is not only reported by us previously [1] [6] [7] but also reported by many researchers [8]-[13]. However, there is no precedent for such a practical and a long-term usable one. There are some important points can be summarized as photocatalysis-plasma synergy [1] [6]-[9]; Better contact among the photocatalyst surface, the gas phase, and high-energy reactive species generated by plasma region; A large amount of adsorbed charges and a high local electric field with the high permittivity of photocatalyst; Enlargement of reactive surface area and improvement of mass transfer. On the other hand, $\mathrm{O}_{3}$-cut filters using a $\mathrm{MnO}_{2}$-based catalyst in the air-cleaner produce additional reactive species by decomposition of excess $\mathrm{O}_{3}$ [1] [14]. In addition to these important points, the present study has achieved reducing the pressure drop and continuous by-products cleaning on the catalyst surface, led to the high practicalities and the long-term usage of the air-cleaner.

Intriguingly, the removal ratios of the TVOCs concentration decreased by $7 \%$ after the treatment of 12,000 cigarettes of tobacco smoke (of course, $88 \% \pm 1 \%$ of the removal ratios of the TVOCs concentration is enough high) while the removal ratios of the odor concentration and TSPs did not change. These data indicate that VOCs in the air stream inside of the air-cleaner might be adsorbed onto the surface of the filters, reactors, and casing, and be desorbed. However, in this condition, these desorbed VOCs did not affect the odor concentration. Generally, odor concentration is strongly affected by the kind of VOCs [15]-[17] (e.g. toluene shows more than 10 times of odor concentration than xylene at the same TVOCs concentration). Thus, the desorbed VOCs in this research may consist of low odor concentration compounds. Now we are preparing GC-MS analysis of collected air samples to determine the kinds of desorbed VOCs.

\section{Conclusion}

The "coil-shape" photocatalysis-plasma synergistic reactor and its application for the practical air-cleaner were investigated. Compared with the previously reported "sandwich-shape" reactor, the "coil-shape" reactor 
achieved $82 \%, 81 \%$, and $25 \%$ reduction of electrostatic capacity, pressure drop, and noise level, respectively. Although only the "single-pass" of 8 cigarettes of tobacco smoke was in the test room, the practical air-cleaner using "coil-shape" reactor reduced by $\geq 98,98.5 \pm 0.1$, and $95 \% \pm 1 \%$ of the odor concentration, TSPs, and TVOCs concentration, respectively. Moreover, Air-purification activity of the air-cleaner was kept at high-level $(\geq 98,98.9 \pm 0.1$, and $88 \% \pm 1 \%$ reduction of the odor concentration, TSPs, and TVOCs concentration, respectively) after the treatment of 12,000 cigarettes of tobacco smoke, which was equivalent to using the air-cleaner in the smoking room for a half year. This research shows that the coil-shape reactor property is good enough to remove tobacco smoke compounds for practical use and the continuous improvement of the reactor design leads the creation of effective environmental purification systems.

\section{Acknowledgements}

The authors are grateful to Mr. N. Uchiyama, Mr. H. Inoue and Mr. H. Kasagi (I’m PACT World Co., Ltd.) for the experiments and helpful discussions.

\section{References}

[1] Ochiai, T., Hayashi, Y., Ito, M., Nakata, K., Murakami, T., Morito, Y. and Fujishima, A. (2012) An Effective Method for a Separation of Smoking Area by Using Novel Photocatalysis-Plasma Synergistic Air-Cleaner. Chemical Engineering Journal, 209, 313-317. http://dx.doi.org/10.1016/j.cej.2012.07.139

[2] Chen, X., Rozak, J., Lin, J.-C., Suib, S.L., Hayashi, Y. and Matsumoto, H. (2001) Oxidative Decomposition of Chlorinated Hydrocarbons by Glow Discharge in PACT (Plasma and Catalyst Integrated Technologies) Reactors. Applied Catalysis A: General, 219, 25-31. http://dx.doi.org/10.1016/S0926-860X(01)00644-5

[3] Ochiai, T., Hoshi, T., Slimen, H., Nakata, K., Murakami, T., Tatejima, H., Koide, Y., Houas, A., Horie, T., Morito, Y. and Fujishima, A. (2011) Fabrication of $\mathrm{TiO}_{2}$ Nanoparticles Impregnated Titanium Mesh Filter and Its Application for Environmental Purification Unit. Catalysis Science \& Technology, 1, 1324-1327.

http://dx.doi.org/10.1039/C1CY00185J

[4] Yang, S.B. (2003) A Comparative Study on Odor Regulation in Japan and Korea. Odor Measurement Review, Ministry of the Environment Government of Japan, Tokyo, 77-81.

[5] Wolkoff, P. (1998) Impact of Air Velocity, Temperature, Humidity, and Air on Long-Term Voc Emissions from Building Products. Atmospheric Environment, 32, 2659-2668. http://dx.doi.org/10.1016/S1352-2310(97)00402-0

[6] Ochiai, T., Nakata, K., Murakami, T., Morito, Y., Hosokawa, S. and Fujishima, A. (2011) Development of an Air-Purification Unit Using a Photocatalysis-Plasma Hybrid Reactor. Electrochemistry, 79, 838-841. http://dx.doi.org/10.5796/electrochemistry.79.838

[7] Ochiai, T. and Fujishima, A. (2012) Photoelectrochemical Properties of $\mathrm{TiO}_{2}$ Photocatalyst and Its Applications for Environmental Purification. Journal of Photochemistry and Photobiology C: Photochemistry Reviews, 13, $247-262$. http://dx.doi.org/10.1016/j.jphotochemrev.2012.07.001

[8] Guaitella, O., Thevenet, F., Puzenat, E., Guillard, C. and Rousseau, A. (2008) $\mathrm{C}_{2} \mathrm{H}_{2}$ Oxidation by Plasma/TiO $\mathrm{O}_{2}$ Combination: Influence of the Porosity, and Photocatalytic Mechanisms under Plasma Exposure. Applied Catalysis B: Environmental, 80, 296-305. http://dx.doi.org/10.1016/j.apcatb.2007.11.032

[9] Van Durme, J., Dewulf, J., Leys, C. and Van Langenhove, H. (2008) Combining Non-Thermal Plasma with Heterogeneous Catalysis in Waste Gas Treatment: A Review. Applied Catalysis B: Environmental, 78, 324-333. http://dx.doi.org/10.1016/j.apcatb.2007.09.035

[10] Nasonova, A., Pham, H.C., Kim, D.J. and Kim, K.S. (2010) NO and $\mathrm{SO}_{2}$ Removal in Non-Thermal Plasma Reactor Packed with Glass Beads- $\mathrm{TiO}_{2}$ Thin Film Coated by PCVD Process. Chemical Engineering Journal, 156, 557-561. http://dx.doi.org/10.1016/j.cej.2009.04.037

[11] Wang, T.C., Lu, N., Li, J. and Wu, Y. (2011) Plasma-TiO ${ }_{2}$ Catalytic Method for High-Efficiency Remediation of p-Nitrophenol Contaminated Soil in Pulsed Discharge. Environmental Science \& Technology, 45, 9301-9307. http://dx.doi.org/10.1021/es2014314

[12] Huang, H.B., Ye, D.Q. and Leung, D.Y.C. (2010) Removal of Toluene Using UV-Irradiated and Nonthermal PlasmaDriven Photocatalyst System. Journal of Environmental Engineering-ASCE, 136, 1231-1236. http://dx.doi.org/10.1061/(asce)ee.1943-7870.0000268

[13] Wang, H.-J. and Chen, X.-Y. (2011) Kinetic Analysis and Energy Efficiency of Phenol Degradation in a Plasma-Photocatalysis System. Journal of Hazardous Materials, 186, 1888-1892. http://dx.doi.org/10.1016/j.jhazmat.2010.12.088 
[14] Jarrige, J. and Vervisch, P. (2009) Plasma-Enhanced Catalysis of Propane and Isopropyl Alcohol at Ambient Temperature on a $\mathrm{MnO}_{2}$-Based Catalyst. Applied Catalysis B: Environmental, 90, 74-82. http://dx.doi.org/10.1016/j.apcatb.2009.02.015

[15] Knudsen, H.N., Kjaer, U.D., Nielsen, P.A. and Wolkoff, P. (1999) Sensory and Chemical Characterization of VOC Emissions from Building Products: Impact of Concentration and Air Velocity. Atmospheric Environment, 33, 12171230. http://dx.doi.org/10.1016/S1352-2310(98)00278-7

[16] Wolkoff, P., Wilkins, C.K., Clausen, P.A. and Nielsen, G.D. (2006) Organic Compounds in Office EnvironmentsSensory Irritation, Odor, Measurements and the Role of Reactive Chemistry. Indoor Air, 16, 7-19. http://dx.doi.org/10.1111/j.1600-0668.2005.00393.x

[17] Uhde, E. and Salthammer, T. (2007) Impact of Reaction Products from Building Materials and Furnishings on Indoor Air Quality-A Review of Recent Advances in Indoor Chemistry. Atmospheric Environment, 41, 3111-3128. http://dx.doi.org/10.1016/j.atmosenv.2006.05.082 